\title{
Analysis of Event Sequences in Power Distribution Systems
}

\author{
O. A. Quiroga ${ }^{1}$, J. Melendez $^{1}$, S. Herraiz ${ }^{1}$ and J. Sánchez ${ }^{2}$ \\ ${ }^{1}$ Institute of Informatics and Applications \\ Girona University \\ Campus Montilivi - Av. Lluis Santaló, 17071 Girona (Spain) \\ Phone/Fax number: +34 972 418486, e-mail: \{ $\underline{\text { oscar.quiroga, joaquim.melendez, sergio.herraiz }\} \text { udg.edu }}$ \\ ${ }^{2}$ Endesa Distribución Eléctrica SLU \\ E-mail: jslosada@endesa.es
}

\begin{abstract}
In this paper, events registered in power distribution systems are analyzed to recognize sequences of events associated to faults occurred in the network. The events considered in this study are basically voltage sags generated by homopolar faults and registered by power quality monitors installed in the secondary of transformers in distribution substations. The events registered in a measuring point have associated the time of occurrence, and the list of increasingtime ordered events corresponds to a sequence. The aim of this work is to discover the collection of events associated with failures in the network that can be viewed as sequences of events related with the actuation of the protection system. Two algorithms are proposed to recognize these sequences. The methodology is tested with data gathered in different substations which have been manual grouped by the utility ${ }^{1}$.
\end{abstract}

\section{Key words}

Power quality, sequence pattern discovery, voltage sag, event sequence, frequent episodes.

\section{Introduction}

A typical power distribution system is composed of hundreds of individual components such as transformers, cables, switches, insulators, surge arresters, etc. The failure of a single component cause problems related with power quality and reliability both in the affected circuit and others adjacent circuits [1]. In recent years the size and complexity of power distribution networks have been increasing, so the number of failures are also increasing. These failures can be due to external causes such as lightning, snow, rain, etc., or to degradation of components.

Electrical components of a network present degradation when his normal designed limits of work are exceeded. In addition, a phenomenon called fatigue is produced when they are subjected to dynamic cyclical workloads which may be less than rated work load.

\footnotetext{
${ }^{1}$ ENDESA Distribución SLU
}

When a fault occurs in an electrical network, the system protections actuate to remove or to isolate the point or network section failed and be able to supply energy to the rest of the system. Faults cause voltage dips whose duration depends on the time of operation of the protection system. Then, the voltage sags are a reflection of the failures that occurring in the system. The records of these events allow to analyze the fault magnitude, location, etc [1].

Voltage sags are usually accompanied by other effects such as overcurrent and overvoltage, which may eventually cause damage to other network components. Overcurrent increases the temperature of the wires, which results in premature degradation in the dielectric isolation. Also, overcurrents affect the mechanical strength of the bus bar or connectors. Likewise, overvoltages deteriorate the insulation and its effects are cumulative [2].

Incipient faults occur when network component are beginning to degrade. For example, abnormal and intermittent variations of voltage and/or current, which becomes more frequent and visible until final damage occurs [3].

This work analyzes the historical records of events collected over two years in 48 substations of a power distribution system. Events are phenomena which only happen once in a while and can be described by parameters as depth and duration (voltage sags). To describe sequences of events we need also to include the time between consecutive events in the description (all these parameters in stochastic sense). "Voltage events" (interruptions, transient overvoltage and voltage sags) are the main class of events, but only voltage sags are considered in this work. Origin of voltage sags is diverse but they can reflect faults occurring in the power distribution system and are characterised by a reduction in the supply voltage magnitude (depth) followed by a voltage recovery after a short period of time (duration). According to IEC, a supply voltage sag is a sudden reduction in the supply voltage to a value between $90 \%$ 
and $1 \%$ of the declared voltage, followed by a recovery between $10 \mathrm{~ms}$ and 1 minute later. For the IEEE a voltage drop is only sag if the during-sag voltage is between $10 \%$ and $90 \%$ of the nominal voltage [1].

\section{A. Dataset Description}

The database available contains the events recorded over two years in the lower voltage level of several substations $(132 / 25 \mathrm{kV}, 110 / 25 \mathrm{kV})$ of power distribution network. Table I shows an example of events recorded in a substation. Each row in Table I corresponds to an event. Each logged event has six attributes: index is the occurrence order of the events; t_begin is the date of occurrence of the event; devent is the duration of the event in the network; pevent is the depth of the voltage sag generated by the event and corresponds to the percentage that the RMS voltage value decreases during the event; vpeak is the percentage that the RMS voltage value increases during the event; phases_afect shows the phases affected by the event and describes if the voltage decreases " $H$ " or increases " $S$ " preceded by the identifier of the respective phase $(1,2$ or 3$)$.

Table I. - Example of Events Registered in Several Substations

\begin{tabular}{|c|c|c|c|c|c|}
\hline Index & t_begin & $\begin{array}{c}\text { devent } \\
\text { (s) }\end{array}$ & $\begin{array}{c}\text { pevent } \\
(\%)\end{array}$ & $\begin{array}{l}\text { vpeak } \\
(\%)\end{array}$ & phases_afect \\
\hline 1 & $\begin{array}{c}07-09-22 \\
12: 28: 11.145\end{array}$ & 1,081 & 62 & 70 & $1 \mathrm{~S} 2 \mathrm{~S} 3 \mathrm{H} 2 \mathrm{H}$ \\
\hline 2 & $\begin{array}{c}07-09-22 \\
12: 31: 57.231\end{array}$ & 0,501 & 61 & 68 & $\begin{array}{l}\text { 3S1H2S1S2H1H3H } \\
\text { 1S2S3S }\end{array}$ \\
\hline 3 & $\begin{array}{c}07-09-22 \\
14: 30: 02.287\end{array}$ & 1,001 & 57 & 67 & $1 \mathrm{~S} 2 \mathrm{~S} 3 \mathrm{H} 3 \mathrm{~S} 2 \mathrm{~S}$ \\
\hline 4 & $\begin{array}{c}07-10-21 \\
06: 07: 36.491\end{array}$ & 0,881 & 70 & 62 & $3 \mathrm{~S} 1 \mathrm{H} 2 \mathrm{~S} 1 \mathrm{~S} 3 \mathrm{~S}$ \\
\hline 5 & $\begin{array}{c}07-10-22 \\
14: 57: 10.262\end{array}$ & 0,760 & 75 & 74 & $1 \mathrm{~S} 3 \mathrm{~S} 2 \mathrm{H} 2 \mathrm{~S} 3 \mathrm{~S} 1 \mathrm{~S}$ \\
\hline 6 & $\begin{array}{c}07-12-25 \\
21: 44: 24.553 \\
\end{array}$ & 0,862 & 61 & 67 & $\begin{array}{l}1 \mathrm{H} 2 \mathrm{~S} 3 \mathrm{~S} 2 \mathrm{H} 3 \mathrm{H} 3 \mathrm{~S} 1 \mathrm{~S} \\
2 \mathrm{~S}\end{array}$ \\
\hline 7 & \begin{tabular}{|c|}
$08-01-20$ \\
$18: 05: 02.142$ \\
\end{tabular} & 1,100 & 64 & 57 & $2 \mathrm{~S} 1 \mathrm{~S} 3 \mathrm{H} 3 \mathrm{~S} 1 \mathrm{~S}$ \\
\hline
\end{tabular}

\section{Problem Statement}

The main goal is the identification of event sequences related with the occurrence of faults in network components. The selection of the attributes of the recorded events that are useful in the description and discovery of such patterns will be studied.

In presence of damages, multiple events can be generated due to the actuation (automatic and manual) of the protection system during the fault, which isolates and locates the area where it has been originated. In consequence, pattern sequences described by those faults can be diverse. In case of auto-extinguishing faults, the number of successive events generated will be lower than when there is a permanent damage according to the number of times that the protection system operates (openings and reclosings) in order to clear the fault. Additionally, voltage sags of events related whit the same fault should show similar depths and durations. Also, different sequences of events with similarities in their attributes will indicate that have occurred in the same area or region of the network.

Table II shows typical reclosing settings (automatic and manual coordination strategies) for a distribution network with overhead and underground lines. Reclosing strategy depends on the line to protect. In this case there are four options for reclosing different types of line, as it is shown in Table II

Table II. - Typical Reclosing Settings in Distribution Systems

\begin{tabular}{|c|c|c|c|c|}
\hline $\begin{array}{l}\text { PHASE OF } \\
\text { RECLOSING }\end{array}$ & $\begin{array}{c}\text { OPTION } \\
1 \\
\end{array}$ & $\begin{array}{c}\text { OPTION } \\
2 \\
\end{array}$ & $\begin{array}{c}\text { OPTION } \\
3 \\
\end{array}$ & $\begin{array}{c}\text { OPTION } \\
4 \\
\end{array}$ \\
\hline Fault detection & $5 \mathrm{~ms}$ & $5 \mathrm{~ms}$ & $5 \mathrm{~ms}$ & $5 \mathrm{~ms}$ \\
\hline Automatic reclosing & $500 \mathrm{~ms}$ & $500 \mathrm{~ms}$ & $500 \mathrm{~ms}$ & $500 \mathrm{~ms}$ \\
\hline $\begin{array}{l}\text { Slow automatic } \\
\text { reclosing }\end{array}$ & $40 \mathrm{~s}$ & $1 \mathrm{~min}$ & $40 \mathrm{~s}$ & $1 \mathrm{~min}$ \\
\hline $\begin{array}{l}\text { Manual reclosing } \\
\text { overhead line }\end{array}$ & ------- & -------- & $3 \mathrm{~min}$ & $3 \mathrm{~min}$ \\
\hline $\begin{array}{l}\text { Manual reclosing } \\
\text { underground cables }\end{array}$ & $1 \mathrm{~min}$ & $1 \mathrm{~min}$ & ------- & ------- \\
\hline $\begin{array}{l}\text { Handling } \\
\text { (telecontrol) }\end{array}$ & $8 \mathrm{~min}$ & $8 \mathrm{~min}$ & $8 \mathrm{~min}$ & $8 \mathrm{~min}$ \\
\hline Handling (on-site) & $25 \mathrm{~min}$ & $25 \mathrm{~min}$ & $25 \mathrm{~min}$ & $25 \mathrm{~min}$ \\
\hline \multicolumn{5}{|c|}{$\begin{array}{l}\text { Option 1: underground cables type } 1 \\
\text { Option 2: underground cables type } 2 \\
\text { Option 3: overhead lines type } 1 \\
\text { Option 4: overhead lines type } 2\end{array}$} \\
\hline
\end{tabular}

If $D$ is a set of events registered in the same substation of the system as showed in Table $1, D$ can be written as: $\boldsymbol{D}=\left\langle\left(\boldsymbol{A}_{\mathbf{1}}, \mathbf{t}_{\mathbf{1}}\right),\left(\mathbf{A}_{\mathbf{2}}, \mathbf{t}_{\mathbf{2}}\right), \ldots,\left(\mathbf{A}_{\mathbf{n}}, \mathbf{t}_{\mathbf{n}}\right)\right\rangle$, where an event is a pair $\left(A_{i}, t_{i}\right), A_{i}$ is the type of event (an event can have different attributes) and $t_{i}$ is the instant of occurrence. $A_{l}$ is the first event and $A_{n}$ is the last event. Given that at the same point of fault can pertain several events, then set $D$ can be viewed as $D=\left\langle\left(S_{1},\left[t_{s 1}, t_{e 1}\right]\right),\left(S_{2},\left[t_{s 2}, t_{e 2}\right]\right), \ldots,\left(S_{k},\left[t_{s n}, t_{e n}\right]\right)\right\rangle$ where $S_{i}$ is a subset of events related whit the same point of fault, $t_{s i}$ is the star time of the subsequence $i$ and $t_{e i}$ is the end time of the subsequence $i$. The discovery of these subsequences is based on a criteria of similarities between attributes of events and considering also the temporal proximity of occurrence.

One criteria in the analysis is to group the nearest events. If $w$ is the time constraint and if $t_{1}, t_{2}, \ldots, t_{n}$ are the sort dates of the events then the subsets of events $\left\langle\left(\boldsymbol{A}_{i}, \boldsymbol{t}_{\boldsymbol{i}}\right), \ldots\left(\boldsymbol{A}_{\boldsymbol{k}}, \boldsymbol{t}_{\boldsymbol{k}}\right)\right\rangle$ such that $\boldsymbol{t}_{\boldsymbol{k}}-\boldsymbol{t}_{\boldsymbol{i}} \leq \boldsymbol{w}$ are probably produced in the same point of failure. Another criteria is to verify that the events within a temporal window occur in the same phase and to define a percentage of similarities between depths of events classified in the same sub-set through these two considerations.

\section{State of the Art}

Pattern discovery in sequential data has been widely applied in different fields (financial series, alarms in communication networks, sequences of queries in databases, sequences of customer transactions, etc.) but never to characterise and predict faults in power systems. The common goal in those domains is to automatically discover interesting patterns according to different criteria [4]; but depending on the nature of the data, the 
identification of patterns can follow different approaches. For example, if the dataset consists of a collection of sequences containing different items, the task may be to discover ordered subsequences of items that occur in many of these sequences (sequential patterns [5]). On the other hand, if the dataset consists of a unique and extensive sequence, the task may be focused on discovering temporal patterns that occur many times throughout the sequence (frequent episodes [6]). This approach has been used for mining data from assembly lines in manufacturing plants [7] and to analyze neurobiological data [8] under some explicit time constraints with respect to the original approach. Another exiting approach is based on the assumption that in an event sequence there are events at each time slot in terms of various intervals (hours, days, weeks, etc.) such sequences must satisfy more complex representation [9].

Development of automatic strategies for dealing with power quality monitoring problems (disturbance recognition and classification, failure analysis and forecasting, fault location, etc.) in power distribution systems are present topics. An extensive review and formulation of problems related to power quality, focusing primarily on voltage sags and interruptions can be found in [1]. Incipient fault detection and analysis of failures is a recent topic of great interest for the development of predictive maintenance policies of the electrical system. For example, in [9] abnormal and intermittent variations of voltages and/or currents are studied for an early recognition of apparition of those incipient faults. The idea of analyzing the evolution of incipient faults is introduced in [3] and [10] and it is based on the identification of parameters that can predict failures of components. An artificial intelligence methodology to predict and detect faults at an early stage in power systems is used in [11]. Artificial neural networks (ANNs) are employed to monitor the states of some components in power networks, such as switchgears and transformers, with the aim of detecting and alerting the operator before a catastrophic fault occurs. Fault distribution modelling for stochastic prediction of voltage sags in power networks are developed in [12] and [13] with the goal of predicting the performance of the power network under transient conditions. A fault diagnosis model, based on data mining of sequences of events (SOE), for fault diagnosis of high-voltage transmission line systems (HVTLS) is presented in [14]. SOE is a log that records the signals and alarms produced by the protection systems and the proposed model makes use of spatio-temporal characteristics contained in the SOE logs to identify faulty components based on real-time alarm information occurred in accidents.

\section{Recognition of Events Sequences Related whit Individual Faults}

Given a set of events identified as homopolar faults, sorted by their time of occurrence, the proposed solution shows a first development to find the sub-sets of events related with a particular point of fault, based on the recognition of the nearest events beginning from the date of occurrence of the event. The assumption is that, according to Table II , a permanent fault will have successive near events by the actuation of the protection system. The necessary information is contained in the attribute "t_begin", as it is shown in Table I. An algorithm development to solve the problem is showed below.

\author{
Algorithm 1. \\ Input: A sorted set $D$ of $n$ successive homopolar faults, a \\ temporal window width $w$. \\ Output: A set of events identified with the index \\ "id_fault" of corresponding event sequence. \\ Method: \\ 1. for $\mathrm{i}:=1$ to $n-1$ do \\ 2. if $t \_$begin (event $\left.i+1\right)-t \_$begin (event $\left.i\right)<=w$ \\ then group in the same id_fault; \\ 3. Output id_fault;
}

A second solution is based on the similarities of the duration, depth and faulted phases, since the assumptions are that for a particular fault the events will be similar too. The necessary information is contained in the attributes "d_event", "pevent" and "phases_afect", as it is shown in Table I. An algorithm development to solve the problem is showed below.

\section{Algorithm 2.}

Input: A sorted set $D$ of $n$ successive homopolar faults, a threshold of similarity in the depth of the events $t h$, a threshold of similarity in the duration of the events $t d$, and a maximum temporal width $w$.

Output: A set of events identified with the index "id_fault" of corresponding event sequence.

Method:

1. for $\mathrm{i}:=1$ to $n-1$ do

2. if $\mid$ devent $i-$ devent $i+1 \mid<=t d$ and pevent $i-$ pevent $i+1 \mid<=$ th and $t \_$begin (event $\left.i+1\right)-t \_$begin (event $i$ ) $<=w$ and (phases_afect $i \mathbb{0}$ phases affect $i+1) \neq \varnothing$ then group in the same $i d \_$fault;

3. Output id_fault;

To intersection of the phases affected only the phases with voltage depth are compared.

\section{Test of Proposed Solution}

The proposed solution to recognize the events sequences related whit individual point of failure was tested with a database that contains about of 3000 events classified manually by the utility. It is shown the test for a measurement point of the network to illustrate the results of the algorithms. For this point, 18 faults were identified manually across to six months. These faults resulted in a total of 40 events.

Table III shows the results of the analysis of the events classified through the algorithm 1 that are equal to the obtained by manual grouping. A total of 14 faults (78\%) and 26 events $(65 \%)$ were recognized the same as the grouping made by the utility. The only attribute taken 
into account was "t_begin" with a temporal width $w$ equal to 3 hours.

Table III. - Events Sequences Recognized by Algorithm 1 in the same way as Manual Grouping in one Measurement Point

\begin{tabular}{|c|c|c|c|c|c|}
\hline id_fault & t_begin & devent & pevent & vpeak & phases_afec \\
\hline \multirow{7}{*}{1} & $\begin{array}{c}08-01-20 \\
18: 05: 02.142\end{array}$ & 1.1 & 64 & 57 & 2S1S3H3S1S \\
\hline & $\begin{array}{c}08-01-20 \\
18: 05: 03.762 \\
\end{array}$ & 1.34 & 60 & 58 & 2S1S3H3S2S3S \\
\hline & $\begin{array}{c}08-01-20 \\
18: 06: 05.132\end{array}$ & 1.119 & 63 & 56 & $3 \mathrm{H} 2 \mathrm{~S} 1 \mathrm{~S}$ \\
\hline & $\begin{array}{c}08-01-20 \\
21: 04: 25.999 \\
\end{array}$ & 1.181 & 66 & 55 & $1 \mathrm{~S} 3 \mathrm{H} 2 \mathrm{~S}$ \\
\hline & $\begin{array}{c}08-01-20 \\
22: 15: 27.612 \\
\end{array}$ & 1.08 & 68 & 59 & 3H1S2S3S2S1S \\
\hline & $\begin{array}{c}08-01-20 \\
22: 49: 18.041 \\
\end{array}$ & 1.04 & 69 & 58 & 1S2S3H3S3S1S \\
\hline & $\begin{array}{c}08-01-20 \\
23: 57: 43.211 \\
\end{array}$ & 1.001 & 70 & 63 & 2S1S3H3S1S2S \\
\hline 2 & $\begin{array}{c}08-02-09 \\
22: 29: 11.768 \\
\end{array}$ & 0.681 & 85 & 69 & $1 \mathrm{~S} 3 \mathrm{~S} 2 \mathrm{H} 2 \mathrm{~S} 3 \mathrm{~S}$ \\
\hline \multirow{3}{*}{3} & $\begin{array}{c}08-03-05 \\
\text { 08:08:20.552 } \\
\end{array}$ & 0.702 & 84 & 66 & $1 \mathrm{~S} 3 \mathrm{H} 2 \mathrm{~S} 3 \mathrm{~S} 2 \mathrm{~S} 3 \mathrm{~S}$ \\
\hline & $\begin{array}{c}08-03-05 \\
08: 21: 05.488 \\
\end{array}$ & 0.582 & 71 & 65 & $\begin{array}{l}\text { 1S3H2S1H1S3 } \\
\text { S1S2S }\end{array}$ \\
\hline & $\begin{array}{c}08-03-05 \\
08: 50: 02.052 \\
\end{array}$ & 0.562 & 71 & 66 & $\begin{array}{l}\text { 2S3H1S1H1S3 } \\
\text { S2S3S }\end{array}$ \\
\hline 4 & $\begin{array}{c}08-03-15 \\
10: 16: 42.588 \\
\end{array}$ & 0.981 & 56 & 63 & 3S1S2H1S2S3S \\
\hline \multirow{3}{*}{5} & $\begin{array}{c}08-03-27 \\
08: 00: 27.797 \\
\end{array}$ & 0.762 & 83 & 65 & $2 \mathrm{~S} 3 \mathrm{H} 1 \mathrm{~S} 3 \mathrm{~S} 3 \mathrm{~S}$ \\
\hline & $\begin{array}{c}08-03-27 \\
08: 00: 29.059 \\
\end{array}$ & 0.94 & 75 & 63 & $1 \mathrm{~S} 3 \mathrm{H} 2 \mathrm{~S} 3 \mathrm{~S} 3 \mathrm{~S}$ \\
\hline & $\begin{array}{c}08-03-27 \\
08: 01: 30.017 \\
\end{array}$ & 0.98 & 69 & 60 & 1S3H2S3S2S3S \\
\hline 6 & $\begin{array}{c}08-03-27 \\
08: 02: 42.449 \\
\end{array}$ & 0.321 & 65 & 57 & $\begin{array}{l}1 \mathrm{~S} 3 \mathrm{H} 2 \mathrm{~S} 2 \mathrm{H} 2 \mathrm{H} 3 \\
\text { S2S }\end{array}$ \\
\hline 7 & $\begin{array}{c}08-03-27 \\
08: 02: 42.449 \\
\end{array}$ & 0.321 & 65 & 57 & $\begin{array}{l}1 \mathrm{~S} 3 \mathrm{H} 2 \mathrm{~S} 2 \mathrm{H} 2 \mathrm{H} 3 \\
\text { S2S }\end{array}$ \\
\hline \multirow{3}{*}{8} & $\begin{array}{c}08-03-27 \\
08: 02: 43.329 \\
\end{array}$ & 0.918 & 65 & 57 & $3 \mathrm{~S} 1 \mathrm{~S} 2 \mathrm{H} 2 \mathrm{~S}$ \\
\hline & $\begin{array}{c}08-03-27 \\
08: 03: 44.296 \\
\end{array}$ & 0.94 & 65 & 57 & $1 \mathrm{~S} 3 \mathrm{~S} 2 \mathrm{H}$ \\
\hline & $\begin{array}{c}08-03-27 \\
08: 05: 15.980 \\
\end{array}$ & 0.999 & 61 & 57 & $1 \mathrm{~S} 3 \mathrm{~S} 2 \mathrm{H}$ \\
\hline 9 & $\begin{array}{c}08-04-14 \\
15: 19: 32.423 \\
\end{array}$ & 0.24 & 71 & 25 & $\begin{array}{l}\text { 1H3H2H3S2S1 } \\
\mathrm{S}\end{array}$ \\
\hline 10 & $\begin{array}{c}08-04-14 \\
15: 19: 32.423 \\
\end{array}$ & 0.24 & 71 & 25 & $\begin{array}{l}\text { 1H3H2H3S2S1 } \\
\text { S }\end{array}$ \\
\hline 11 & $\begin{array}{c}08-05-26 \\
01: 44: 54.305 \\
\end{array}$ & 0.681 & 76 & 69 & $\begin{array}{l}\text { 2S3S1H2H3H1 } \\
\text { S2S3S2S3S1S }\end{array}$ \\
\hline 12 & $\begin{array}{c}08-06-06 \\
20: 26: 53.125 \\
\end{array}$ & 1.14 & 64 & 61 & $2 \mathrm{~S} 1 \mathrm{~S} 3 \mathrm{H} 3 \mathrm{~S} 1 \mathrm{~S} 2 \mathrm{~S}$ \\
\hline 13 & $\begin{array}{c}08-06-17 \\
14: 53: 06.335\end{array}$ & 0.881 & 70 & 67 & $3 \mathrm{~S} 2 \mathrm{~S} 1 \mathrm{H} 1 \mathrm{~S}$ \\
\hline 14 & $\begin{array}{c}08-07-09 \\
20: 39: 49.360 \\
\end{array}$ & 0.821 & 72 & 71 & $\begin{array}{l}\text { 1H3S2S1S3S2S } \\
3 \mathrm{~S}\end{array}$ \\
\hline
\end{tabular}

In Table III, "id_fault" identifies the fault and it contains the event sequence related with it an observation of the attributes of the events shows that, for a fault, the events can have differences in their features. For example, in the id_fault number 3 , the first event has a depth and duration larger than the others events of the sequence. These dissimilarities may difficult the correct recognition of the event sequences associates to a particular fault.
For the same measurement point, Table IV shows the rest of the events which were not classified as the same way as manual grouping made by the utility.

Table IV. - Events Sequences No Recognized by Algorithm 1 in similar groups that Manual Grouping in one Measurement Point

\begin{tabular}{|c|c|c|c|c|c|c|}
\hline $\begin{array}{c}\text { manual } \\
\text { grouping }\end{array}$ & $\begin{array}{l}\text { calculated } \\
\text { id_fault }\end{array}$ & t_begin & devent & pevent & vpeak & phases_afec \\
\hline 15 & \multirow{9}{*}{15} & $\begin{array}{c}08-03-09 \\
19: 06: 05.905\end{array}$ & 0.441 & 57 & 21 & $\begin{array}{l}3 \mathrm{H} 1 \mathrm{H} 2 \mathrm{H} 2 \\
\text { S1S3S }\end{array}$ \\
\hline 16 & & $\begin{array}{c}08-03-09 \\
19: 06: 06.926\end{array}$ & 0.779 & 73 & 70 & $\begin{array}{l}\text { 2S3S1H1S } \\
\text { 2H2S1S2S }\end{array}$ \\
\hline \multirow{7}{*}{17} & & $\begin{array}{c}08-03-09 \\
19: 06: 08.225\end{array}$ & 0.78 & 73 & 67 & $\begin{array}{l}\text { 2H1S3S2S } \\
\text { 1S2S }\end{array}$ \\
\hline & & $\begin{array}{c}08-03-09 \\
19: 07: 09.020\end{array}$ & 0.762 & 73 & 68 & $\begin{array}{l}2 \mathrm{H} 1 \mathrm{~S} 3 \mathrm{~S} 2 \mathrm{~S} \\
1 \mathrm{~S} 2 \mathrm{~S} \\
\end{array}$ \\
\hline & & $\begin{array}{c}08-03-09 \\
19: 13: 23.244\end{array}$ & 0.741 & 73 & 67 & $3 \mathrm{~S} 1 \mathrm{~S} 2 \mathrm{H} 2 \mathrm{~S}$ \\
\hline & & $\begin{array}{c}08-03-09 \\
21: 04: 29.830\end{array}$ & 0.762 & 73 & 68 & $\begin{array}{l}\text { 1S3S2H2S } \\
\text { 3S1S }\end{array}$ \\
\hline & & $\begin{array}{c}08-03-09 \\
21: 52: 07.769\end{array}$ & 0.761 & 73 & 75 & $\begin{array}{l}\text { 2H1S3S2S } \\
\text { 3S1S }\end{array}$ \\
\hline & & $\begin{array}{c}08-03-09 \\
22: 25: 53.196\end{array}$ & 0.8 & 73 & 68 & $\begin{array}{l}\text { 2H3S1S2S } \\
1 \mathrm{~S} 2 \mathrm{~S} 1 \mathrm{~S}\end{array}$ \\
\hline & & $\begin{array}{c}08-03-09 \\
22: 59: 58.284\end{array}$ & 0.781 & 73 & 69 & $\begin{array}{l}\text { 1S2H3S2S } \\
1 \mathrm{~S} 2 \mathrm{~S} 3 \mathrm{~S}\end{array}$ \\
\hline \multirow{5}{*}{18} & \multirow{4}{*}{16} & $\begin{array}{c}08-06-06 \\
20: 26: 53.125 \\
\end{array}$ & 1.14 & 64 & 61 & $\begin{array}{l}\text { 2S1S3H3S } \\
1 \mathrm{~S} 2 \mathrm{~S}\end{array}$ \\
\hline & & $\begin{array}{c}08-06-06 \\
20: 26: 54.785 \\
\end{array}$ & 1.039 & 67 & 62 & $\begin{array}{l}\text { 1S2S3H3S } \\
2 \mathrm{~S} 1 \mathrm{~S}\end{array}$ \\
\hline & & $\begin{array}{c}08-06-06 \\
20: 27: 55.834\end{array}$ & 0.939 & 70 & 57 & $2 \mathrm{~S} 1 \mathrm{~S} 3 \mathrm{H}$ \\
\hline & & $\begin{array}{c}08-06-06 \\
20: 30: 30.165\end{array}$ & 1.001 & 69 & 57 & $\begin{array}{l}2 \mathrm{~S} 1 \mathrm{~S} 3 \mathrm{H} 3 \mathrm{~S} \\
2 \mathrm{~S}\end{array}$ \\
\hline & 17 & $\begin{array}{c}08-06-07 \\
00: 12: 54.408\end{array}$ & 0.98 & 70 & 58 & $\begin{array}{l}3 \mathrm{H} 2 \mathrm{~S} 1 \mathrm{~S} 3 \mathrm{~S} \\
2 \mathrm{~S}\end{array}$ \\
\hline
\end{tabular}

In Table IV "manual grouping" represents the events sequences that were manually recognized by the utility. Column "calculated id_fault" contains the identifier of the events sequences found by means of Algorithm 1. The sequences found by Algorithm 1 are formed by nearest events in time but the manual grouping shows that the sequences are composed slightly different. In the most of the cases, only the information of the attributes is not enough to recognize the sequences because the attributes are very similar. For example, the "manual grouping" number 16 has an event with the same characteristics that the 7 events that belongs to the "manual grouping” number 17.

Table IV also shows that only considering the nearest events in time is not adequate to find the sequences since in some cases the events can have dissimilarities in its attributes. For example, the first event in the "calculated id_fault" number 15 has a depth and duration lower than the others events in the same sequence.

In short, after analyzing a total of 3378 events by means of algorithm 1, the results showed that $57.5 \%$ of the events were recognized in the same sequences as the obtained by the utility manually.

Algorithm 2 makes use of the other attributes to recognize the sequences. The temporal window of the 
algorithm 1 is replaced by a maximum temporal width $w$ to search the events related with a particular sequence. In this case a $w$ equal to 24 hours is used. Table $\mathrm{V}$ shows the comparative result with the "manual grouping".

Table V. - Events Sequences Recognized by the Algorithm 2 in the same way as Manual Grouping in one Measurement Point

\begin{tabular}{|c|c|c|c|c|c|}
\hline id_fault & t_begin & devent & pevent & vpeak & phases_afec \\
\hline \multirow{7}{*}{1} & $\begin{array}{c}08-01-20 \\
18: 05: 02.142\end{array}$ & 1.1 & 64 & 57 & $\begin{array}{l}\text { 2S1S3H3S1 } \\
\text { S }\end{array}$ \\
\hline & $\begin{array}{c}08-01-20 \\
18: 05: 03.762 \\
\end{array}$ & 1.34 & 60 & 58 & $\begin{array}{l}\text { 2S1S3H3S2 } \\
\text { S3S }\end{array}$ \\
\hline & $\begin{array}{c}08-01-20 \\
18: 06: 05.132 \\
\end{array}$ & 1.119 & 63 & 56 & $3 \mathrm{H} 2 \mathrm{~S} 1 \mathrm{~S}$ \\
\hline & $\begin{array}{c}08-01-20 \\
21: 04: 25.999\end{array}$ & 1.181 & 66 & 55 & $1 \mathrm{~S} 3 \mathrm{H} 2 \mathrm{~S}$ \\
\hline & $\begin{array}{c}08-01-20 \\
22: 15: 27.612 \\
\end{array}$ & 1.08 & 68 & 59 & $\begin{array}{l}\text { 3H1S2S3S2 } \\
\text { S1S }\end{array}$ \\
\hline & $\begin{array}{c}08-01-20 \\
22: 49: 18.041\end{array}$ & 1.04 & 69 & 58 & $\begin{array}{l}\text { 1S2S3H3S3 } \\
\text { S1S }\end{array}$ \\
\hline & $\begin{array}{c}08-01-20 \\
23: 57: 43.211\end{array}$ & 1.001 & 70 & 63 & $\begin{array}{l}\text { 2S1S3H3S1 } \\
\text { S2S }\end{array}$ \\
\hline 2 & $\begin{array}{c}08-02-09 \\
22: 29: 11.768\end{array}$ & 0.681 & 85 & 69 & $\begin{array}{l}\text { 1S3S2H2S3 } \\
\text { S }\end{array}$ \\
\hline \multirow{3}{*}{3} & $\begin{array}{c}08-03-05 \\
08: 08: 20.552\end{array}$ & 0.702 & 84 & 66 & $\begin{array}{l}\text { 1S3H2S3S2 } \\
\text { S3S }\end{array}$ \\
\hline & $\begin{array}{c}08-03-05 \\
08: 21: 05.488\end{array}$ & 0.582 & 71 & 65 & $\begin{array}{l}\text { 1S3H2S1H1 } \\
\text { S3S1S2S }\end{array}$ \\
\hline & $\begin{array}{c}08-03-05 \\
08: 50: 02.052\end{array}$ & 0.562 & 71 & 66 & $\begin{array}{l}\text { 2S3H1S1H1 } \\
\text { S3S2S3S }\end{array}$ \\
\hline 4 & $\begin{array}{c}08-03-09 \\
19: 06: 05.905\end{array}$ & 0.441 & 57 & 21 & $\begin{array}{l}\text { 3H1H2H2S } \\
1 \mathrm{~S} 3 \mathrm{~S}\end{array}$ \\
\hline 5 & $\begin{array}{c}08-03-15 \\
10: 16: 42.588\end{array}$ & 0.981 & 56 & 63 & $\begin{array}{l}\text { 3S1S2H1S2 } \\
\text { S3S }\end{array}$ \\
\hline \multirow{3}{*}{6} & $\begin{array}{c}08-03-27 \\
08: 00: 27.797\end{array}$ & 0.762 & 83 & 65 & $\begin{array}{l}\text { 2S3H1S3S3 } \\
\text { S }\end{array}$ \\
\hline & $\begin{array}{c}08-03-27 \\
08: 00: 29.059\end{array}$ & 0.94 & 75 & 63 & $\begin{array}{l}\text { 1S3H2S3S3 } \\
\text { S }\end{array}$ \\
\hline & $\begin{array}{c}08-03-27 \\
08: 01: 30.017 \\
\end{array}$ & 0.98 & 69 & 60 & $\begin{array}{l}\text { 1S3H2S3S2 } \\
\text { S3S }\end{array}$ \\
\hline 7 & $\begin{array}{c}08-03-27 \\
08: 02: 42.449\end{array}$ & 0.321 & 65 & 57 & $\begin{array}{l}\text { 1S3H2S2H2 } \\
\text { H3S2S }\end{array}$ \\
\hline 8 & $\begin{array}{c}08-03-27 \\
08: 02: 42.449\end{array}$ & 0.321 & 65 & 57 & $\begin{array}{l}\text { 1S3H2S2H2 } \\
\text { H3S2S }\end{array}$ \\
\hline \multirow{3}{*}{9} & $\begin{array}{c}08-03-27 \\
08: 02: 43.329 \\
\end{array}$ & 0.918 & 65 & 57 & $3 \mathrm{~S} 1 \mathrm{~S} 2 \mathrm{H} 2 \mathrm{~S}$ \\
\hline & $\begin{array}{c}08-03-27 \\
08: 03: 44.296 \\
\end{array}$ & 0.94 & 65 & 57 & $1 \mathrm{~S} 3 \mathrm{~S} 2 \mathrm{H}$ \\
\hline & $\begin{array}{c}08-03-27 \\
08: 05: 15.980\end{array}$ & 0.999 & 61 & 57 & 1S3S2H \\
\hline 10 & $\begin{array}{c}08-04-14 \\
15: 19: 32.423\end{array}$ & 0.24 & 71 & 25 & $\begin{array}{l}1 \mathrm{H} 3 \mathrm{H} 2 \mathrm{H} 3 \mathrm{~S} \\
2 \mathrm{~S} 1 \mathrm{~S}\end{array}$ \\
\hline 11 & $\begin{array}{c}08-04-14 \\
15: 19: 32.423\end{array}$ & 0.24 & 71 & 25 & $\begin{array}{l}1 \mathrm{H} 3 \mathrm{H} 2 \mathrm{H} 3 \mathrm{~S} \\
2 \mathrm{~S} 1 \mathrm{~S}\end{array}$ \\
\hline 12 & $\begin{array}{c}08-05-26 \\
01: 44: 54.305\end{array}$ & 0.681 & 76 & 69 & $\begin{array}{l}\text { 2S3S1H2H3 } \\
\text { H1S2S3S2S } \\
\text { 3S1S }\end{array}$ \\
\hline 13 & $\begin{array}{c}08-06-06 \\
20: 26: 53.125\end{array}$ & 1.14 & 64 & 61 & $\begin{array}{l}\text { 2S1S3H3S1 } \\
\text { S2S }\end{array}$ \\
\hline \multirow{5}{*}{14} & $\begin{array}{c}08-06-06 \\
20: 26: 53.125\end{array}$ & 1.14 & 64 & 61 & $\begin{array}{l}\text { 2S1S3H3S1 } \\
\text { S2S }\end{array}$ \\
\hline & $\begin{array}{c}08-06-06 \\
20: 26: 54.785 \\
\end{array}$ & 1.039 & 67 & 62 & $\begin{array}{l}\text { 1S2S3H3S2 } \\
\text { S1S }\end{array}$ \\
\hline & $\begin{array}{c}08-06-06 \\
20: 27: 55.834 \\
\end{array}$ & 0.939 & 70 & 57 & 2S1S3H \\
\hline & $\begin{array}{c}08-06-06 \\
20: 30: 30.165 \\
\end{array}$ & 1.001 & 69 & 57 & $\begin{array}{l}\text { 2S1S3H3S2 } \\
\mathrm{S}\end{array}$ \\
\hline & $\begin{array}{c}08-06-07 \\
00: 12: 54.408\end{array}$ & 0.98 & 70 & 58 & $\begin{array}{l}\text { 3H2S1S3S2 } \\
\text { S }\end{array}$ \\
\hline 15 & $\begin{array}{c}08-06-17 \\
14: 53: 06.335\end{array}$ & 0.881 & 70 & 67 & 3S2S1H1S \\
\hline 16 & $\begin{array}{c}08-07-09 \\
20: 39: 49.360 \\
\end{array}$ & 0.821 & 72 & 71 & $\begin{array}{l}\text { 1H3S2S1S3 } \\
\text { S2S3S }\end{array}$ \\
\hline
\end{tabular}

In this case, all the attributes were taken into account to obtain the sequences. The threshold to the compare the depth th is equal to 15 , the threshold to compare the duration $d h$ is equal to $15 \%$ and the phases_afect whose voltage decreases were compared.

Table $\mathrm{V}$ shows the results of the analysis of the events classified by means of algorithm 2 that are equal to the obtained by manual grouping. A total of 16 fault $(89 \%)$ and 26 events $(80 \%)$ were recognized in the same way as the grouping made by the utility.

For the measurement point analyzed, the results found by Algorithm 2 are better than the obtained by Algorithm 1 .

Table VI. - Events Sequences No Recognized by Algorithm 2 in similar groups that Manual Grouping in one Measurement Point

\begin{tabular}{|c|c|c|c|c|c|c|}
\hline $\begin{array}{l}\text { manual } \\
\text { id_fault }\end{array}$ & $\begin{array}{c}\text { calculated } \\
\text { id_fault }\end{array}$ & t_begin & devent & pevent & vpeak & phases_afec \\
\hline 17 & \multirow{8}{*}{17} & $\begin{array}{c}08-03-09 \\
\text { 19:06:06.926 }\end{array}$ & 0.779 & 73 & 70 & $\begin{array}{l}\text { 2S3S1H1S } \\
\text { 2H2S1S2S }\end{array}$ \\
\hline \multirow{7}{*}{18} & & $\begin{array}{c}08-03-09 \\
19: 06: 08.225\end{array}$ & 0.78 & 73 & 67 & $\begin{array}{l}\text { 2H1S3S2S } \\
1 \mathrm{~S} 2 \mathrm{~S}\end{array}$ \\
\hline & & $\begin{array}{c}08-03-09 \\
19: 07: 09.020\end{array}$ & 0.762 & 73 & 68 & $\begin{array}{l}2 \mathrm{H} 1 \mathrm{~S} 3 \mathrm{~S} 2 \mathrm{~S} \\
1 \mathrm{~S} 2 \mathrm{~S}\end{array}$ \\
\hline & & $\begin{array}{c}08-03-09 \\
19: 13: 23.244\end{array}$ & 0.741 & 73 & 67 & $3 \mathrm{~S} 1 \mathrm{~S} 2 \mathrm{H} 2 \mathrm{~S}$ \\
\hline & & $\begin{array}{c}08-03-09 \\
21: 04: 29.830\end{array}$ & 0.762 & 73 & 68 & $\begin{array}{l}\text { 1S3S2H2S } \\
3 \mathrm{~S} 1 \mathrm{~S}\end{array}$ \\
\hline & & $\begin{array}{c}08-03-09 \\
21: 52: 07.769 \\
\end{array}$ & 0.761 & 73 & 75 & $\begin{array}{l}\text { 2H1S3S2S } \\
3 \mathrm{~S} 1 \mathrm{~S}\end{array}$ \\
\hline & & $\begin{array}{c}08-03-09 \\
22: 25: 53.196\end{array}$ & 0.8 & 73 & 68 & $\begin{array}{l}\text { 2H3S1S2S } \\
1 \mathrm{~S} 2 \mathrm{~S} 1 \mathrm{~S}\end{array}$ \\
\hline & & $\begin{array}{c}08-03-09 \\
22: 59: 58.284\end{array}$ & 0.781 & 73 & 69 & $\begin{array}{l}\text { 1S2H3S2S } \\
1 \mathrm{~S} 2 \mathrm{~S} 3 \mathrm{~S}\end{array}$ \\
\hline
\end{tabular}

The sequences found by Algorithm 2 are formed for events with similarities in all attributes but in Table VI the manual grouping showed that the sequences are composed by other events. Although the sequences found by Algorithm 2 have similarities in all its attributes, the faults can be originated in different elements or circuits of the network because in a measurement point there are several lines monitored. Other problem is that some faults have events that are different from each other, especially in the attributes devent, pevent and vpeak. This occurs because the conditions of fault change along the time (evolutive faults).

In short, a $53.4 \%$ of the totals of events analyzed by Algorithm 2 were recognized in the same event sequences as the manual grouping made by the utility. The global results obtained by the Algorithm 2 are not better than the obtained by the Algorithm 1 for the existence of the evolve faults.

\section{Conclusion}

The analysis of registered events and the proposed solution has shown that useful information about the behavior and evolution of the faults in the electrical system may be extracted, as a first step in the exploitation of events recorded in power distribution systems for the recognition of future failures. 
The test of the proposed solution showed that the assumptions of the problem are not performed in all the cases because the events monitored in a measurement point are associated to the lines that are feed in that point. Then, a overlapping of sequences may occur.

Future work should continue with the search of similarities between different sequences of events associated to faults of specific elements of the network, in order to discover patterns or mine frequent episodes and exploit other information contained in the events recorded.

\section{Acknowledgement}

This research has been developed within the eXiT, Control Engineering and Intelligent Systems, research group of the Institute of Informatics and Applications (University of Girona). eXiT is part of the Automation Engineering and Decision Support Systems (AEDS) research group, awarded with a consolidated distinction (2009 SGR 523) for the 2009-2012 period in the Consolidated Research Group (SGR) project of the Generalitat de Catalunya.

The work has been supported by the research project "Diagnóstico basado en Casos y Modelos de Redes de Distribución Eléctrica" (DPI 2006-09370) and it's continuation "Moniorización Inteligente de la Calidad de la Energía Eléctrica" (DPI2009-07891) funded by Ministerio de Ciencia e Innovación (Spain) and FEDER. Oscar Quiroga, won a PhD scholarship (2009FI-A00452) funded by the Comissionat per a Universitats i Recerca del Departament d'Innovacio, Universitats i Empresa of the Generalitat de Catalunya and also the European Social Fund.

\section{References}

[1] M. Bollen, Understanding Power Quality Problems, Voltage Sags and Interruptions, IEEE press series on power engineering, Piscataway USA (1999).
[2] S. Visacro. Lightning: an Engineering Approach. ArtLiber Edit. Sao Paulo (2005), pp. 1-272.

[3] C. L. Benner and B. D. Russell. "Distribution incipient faults and abnormal events: Case studies from recorded field data". In 57th Annual Conference for Protective Relay Engineers 2004.

[4] S. Laxman and P. S. Sastry, "A Survey of Temporal Data Mining", SADHANA Academy Proceedings in Engineering Sciences 2006, Vol. 31, pp. 173-198.

[5] R. Agrawal and R. Srikant. Mining sequential patterns. In Int. Conf. Data engineering ICDE'95, pages 3-14.

[6] H. Mannila, H. Taitoven and A. I. Verkamo, "Discovery of Frequent Episodes in Event Sequences", Data Mining in Knowledge Discovery 1997, Vol. 1, pp. 259-289.

[7] S. Laxman, P. S. Sastry, and K. P. Unnikrishnan. "Fast algorithms for frequent episode discovery in event sequences". Technical report, CL-2004-04/MSR, GM R\&D Center, Warren (2004).

[8] K. P. Unnikrishnan, D. Patnaik, and P. Sastry. "Discovering patterns in multi-neuronal spike trains using the frequent episode method". Technical report, General Motors R\&D Center, Warren (2007).

[9] K.-Y. Huang and C.-H. Chang. "Efficient mining of frequent episodes from complex sequences". Information Systems 2008, Vol. 33, pp. 96-114.

[10] C. J. Kim, L. Seung-Jae and K. Sang-Hee, "Evaluation of Feeder Monitoring Parameters for Incipient Faults Detection Using Laplace Trent Statistic", IEEE Transactions on Industry Applications 2004, Vol. 40, pp. 17181724.

[11] K. C. P. Wong, H. M. Ryan, and J. Tindle. "Power system fault prediction using artificial neural networks". In International Conference on Neural Information Processing, 1996

[12] B. Q. Khanh, D.-J. Won, and S.-I. Moon. "Fault distribution modeling using stochastic bivariate models for prediction of voltage sag in distribution systems". IEEE Transactions on Power Delivery 2008, Vol. 23, pp. 347-354.

[13] J. A. Martinez-Velasco and J. Martin-Arnedo. "Stochastic prediction of voltage dips using an electromagnetic transient program". In 14th PSCC 2002.

[14] Z. Liao, G. Wang, Q. Ye, and Y. Sun. "A novel fault diagnosis system for transmission line system based on sequence of events". In 6th International Conference on Advances in Power System Control, Operation and Management APSCOM 2003, pp. 440-445. 